\title{
Cytochrome P450 monooxygenase analysis in free-living and symbiotic microalgae Coccomyxa sp. C-169 and Chlorella sp. NC64A
}

\author{
Ntsane Trevor Mthakathi ${ }^{1}$, Ipeleng Kopano Rosinah Kgosiemang ${ }^{1}$, Wanping Chen ${ }^{2}$, \\ Molikeng Eric Mohlatsane ${ }^{1}$, Thebeyapelo Jacob Mojahi ${ }^{1}$, Jae-Hyuk Yu ${ }^{3}$, Samson Sitheni \\ Mashele $^{1}$ and Khajamohiddin Syed ${ }^{1, *}$
}

\author{
${ }^{1}$ Unit for Drug Discovery Research, Department of Health Sciences, Faculty of Health and Environmental Sciences, Central \\ University of Technology, Bloemfontein 9300, Free State, South Africa \\ ${ }^{2}$ College of Food Science and Technology, Huazhong Agricultural University, Wuhan 430070, China \\ ${ }^{3}$ Department of Bacteriology, University of Wisconsin-Madison, 3155 MSB, 1550 Linden Drive, Madison, WI 53706, USA
}

\begin{abstract}
Microalgae research is gaining momentum because of their potential biotechnological applications, including the generation of biofuels. Genome sequencing analysis of two model microalgal species, polar free-living Coccomyxa sp. C-169 and symbiotic Chlorella sp. NC64A, revealed insights into the factors responsible for their lifestyle and unravelled biotechnologically valuable proteins. However, genome sequence analysis under-explored cytochrome P450 monooxygenases (P450s), heme-thiolate proteins ubiquitously present in species belonging to different biological kingdoms. In this study we performed genome data-mining, annotation and comparative analysis of P450s in these two model algal species. Sixty-nine P450s were found in two algal species. Coccomyxa sp. showed 40 P450s and Chlorella sp. showed 29 P450s in their genome. Sixty-eight P450s (>100 amino acid in length) were grouped into 32 P450 families and 46 P450 subfamilies. Among the P450 families, 27 P450 families were novel and not found in other biological kingdoms. The new P450 families are CYP745-CYP747, CYP845-CYP863, and CYP904-CYP908. Five P450 families, CYP51, CYP97, CYP710, CYP745, and CYP746, were commonly found between two algal species and 16 and 11 P450 families were unique to Coccomyxa sp. and Chlorella sp. Synteny analysis and gene-structure analysis revealed P450 duplications in both species. Functional analysis based on homolog P450s suggested that CYP51 and CYP710 family members are involved in membrane ergosterol biosynthesis. CYP55 and CYP97 family members are involved in nitric oxide reduction and biosynthesis of carotenoids. This is the first report on comparative analysis of P450s in the microalgal species Coccomyxa sp. C-169 and Chlorella sp. NC64A.
\end{abstract}

Key Words: carotenoid biosynthesis; Chlorella sp. NC64A; Coccomyxa sp. C-169; cytochrome P450 monooxygenases; nitric oxide reductase; P450nor; symbiosis

\section{INTRODUCTION}

Green algae belonging to the phylum Chlorophyta consist of microorganisms adapted to diverse ecological niches. Green algae are photosynthetic in nature and it is estimated that more than one billion years ago terrestrial plants emerged from these organisms (Heckman et al. 2001). These organisms played a key role during the evo-
(7) \$ This is an Open Access article distributed under the terms of the Creative Commons Attribution Non-Commercial License (http://creativecommons.org/licenses/by-nc/3.0/) which permits unrestricted non-commercial use, distribution, and reproduction in any medium, provided the original work is properly cited.
Received April 3, 2015, Accepted July 6, 2015

* Corresponding Author

E-mail: khajamohiddinsyed@gmail.com Tel: +27-51-507-3425, Fax: +27-51-507-3134 
lutionary history of earth and became major players in global energy / biomass production and biogeochemical recycling (Grossman 2005, Blanc et al. 2010). Among algae, research on microalgae has been intensified because of their enormous biotechnological potential, including generation of biofuels (Behera et al. 2015), phytochemicals (De Jesus Raposo and De Morais 2015), cosmetics (Wang et al. 2015) and vaccines (Specht and Mayfield 2014) and their use in wastewater treatment (Tiron et al. 2015). Microalgae are also used as biomarkers for organic and inorganic pollution (Torres et al. 2008).

Two microalgal species, namely Coccomyxa sp. C-169 (formerly known as Chlorella vulgaris) and Chlorella sp. NC64A (formerly known as Chlorella variabilis NC64A), are of special interest. Coccomyxa sp. is a polar free-living microalga, whereas Chlorella sp. is a photosynthetic endosymbiont (photobiont) of the unicellular protozoan Paramecium bursaria (Karakashian and Karakashian 1965). They both produce lipids and are considered potential candidates for biofuel generation. Coccomyxa sp. is regarded as a model organism to study chromosome repair from irradiation (Blanc et al. 2012) and Chlorella sp. as a model organism to study DNA virus / algal interactions (Blanc et al. 2010). Genome sequencing analysis of these organisms shed light on the critical aspects discussed above, including features needed for free-living and symbiotic lifestyles (Blanc et al. 2010, 2012).

Genome sequencing analysis of these species (Blanc et al. 2010, 2012) under-explored cytochrome P450 monooxygenases (P450s), heme-thiolate proteins present in organisms belonging to all biological kingdoms (Nelson 2013). P450s are known to involve organisms' primary and secondary metabolic reactions. Oxidation of a wide variety of substrates in stereo- and regio-specific manner credited these enzymes' use in the generation of drugs (Ingelman-Sundberg 2004, Guengerich 2006), fine chemicals and cosmetics (Guengerich 2002) and biofuels (Zhang et al. 2011) and as biosensors (Paternolli et al. 2004) and bioremediation agents (Guengerich 1995, Urlacher and Eiben 2006). A summary of P450s' potential biotechnological applications has been discussed elsewhere (Syed and Yadav 2012).

P450s belonging to different biological kingdoms, including animals (inclusive of humans), plants, fungi, and bacteria, have been thoroughly investigated. Despite the great importance of microalgae and the potential biotechnological value of P450s, studies on microalgae P450s are scarce or not reported. In this study, we performed comparative analysis of P450s in the two model microalgal species Coccomyxa sp. C-169 and Chlorella sp. NC64A.

\section{MATERIALS AND METHODS}

The genomes of Coccomyxa sp. C-169 and Chlorella sp. NC64A have been sequenced and their genome sequence data are available for public use (Blanc et al. 2010, 2012). Genome data mining of P450s in the two species was carried out as described elsewhere (Kgosiemang et al. 2014, Syed et al. 2014). Briefly, the proteomes of these species were downloaded from the respective databases: http:// genome.jgi.doe.gov/Coc_C169_1/Coc_C169_1.home. html (Coccomyxa sp. C-169) and http://genome.jgi-psf. org/ChlNC64A_1/ChlNC64A_1.home.html (Chlorella sp. NC64A) and subjected to the NCBI Batch Web-search tool (Marchler-Bauer et al. 2011). Proteins that were grouped under the P450 superfamily were selected and analysed for the presence of P450 family signature motifs, namely the heme-binding motif (EXXR) and oxygen-binding motif (CXG). The proteins that showed both motifs were subjected to blast analysis against all named Protista P450s at the Cytochrome P450 Homepage (Nelson 2009). Families and subfamily names were assigned following the standard rule set by the International P450 Nomenclature Committee, i.e., $>40 \%$ sequence identity for assigning family and $>55 \%$ sequence identity for subfamily (Nelson et al. 1993, Nelson 1998, 2006). The P450s that showed less than $40 \%$ identity to known P450s were submitted to Prof. David R Nelson, University of Tennessee Health Science Centre, Memphis, Tennessee, USA for assigning new P450 families. The annotation for some P450s in these organisms was available at the Cytochrome P450 Homepage (Nelson 2009). In this case we assigned protein IDs to the annotated P450s. Comparison of Cytochrome P450 Homepage and genome databases P450 sequences revealed different predictions of $\mathrm{P} 450$ s for the same genomic location. In this case, both P450s were included where $\mathrm{P} 450$ s were indicated with DP in their names.

The phylogenetic relationship of the annotated algae P450s was inferred as follows: first, all the P450 protein sequences were aligned by ClustalW2 with default parameters (http://www.ebi.ac.uk/Tools/msa/clustalw2/) (Larkin et al. 2007). Then the alignment was subjected to RAxML 7.0.4 at model PROTCATDAYHOFF with 100 bootstrap replications for inferring the phylogenetic tree (Stamatakis 2006). Finally, the generated tree data were submitted to iTOL (http://itol.embl.de/) for displaying the tree (Letunic and Bork 2011).

The physical co-localization of P450 genes on the DNA was identified by searching the algal species genome database using the P450 protein ID. For each P450, its scaffold number, DNA strand and number of introns 
were noted and presented in tabular form. Functional analysis of algal species P450s was predicted based on their functionally characterized homolog(s) in other organisms. Furthermore, to identify the functional role, algal P450s were blasted at Kyoto Encyclopedia of Genes and Genomes (KEGG; http://www.genome.jp/tools/ blast/) and NCBI (http://blast.ncbi.nlm.nih.gov/Blast. cgi?PAGE=Proteins\#) and their functions were predicted based on the best hit proteins with known function.

\section{RESULTS AND DISCUSSION}

Genome-wide data mining and annotation of P450s in the two model microalgal species revealed the presence of 69 P450s (Table 1, Supplementary Fig. S1). Coccomyxa sp. and Chlorella sp. respectively showed 40 and 29 P450s in their genome. All of the P450s in both species were found to be full-length, i.e., $>400$ amino acids in length (Supplementary Fig. S1), with the exception of three

Table 1. Family- and subfamily-level comparative analysis of P450s in two model microalgae, Chlorella sp. NC64A and Coccomyxa sp. C-169

\begin{tabular}{|c|c|c|c|c|}
\hline P450 family & Subfamily & Chlorella sp. NC64A & Coccomyxa sp. C-169 & P450 count \\
\hline CYP51 & $\mathrm{G}$ & 1 & 1 & 2 \\
\hline CYP55 & B & 1 & - & 1 \\
\hline \multirow[t]{3}{*}{ CYP97 } & $\mathrm{A}$ & 1 & 1 & 6 \\
\hline & B & 1 & 1 & - \\
\hline & $\mathrm{C}$ & 1 & 1 & - \\
\hline CYP710 & $\mathrm{B}$ & 1 & 1 & 2 \\
\hline \multirow[t]{2}{*}{ CYP745 } & $\mathrm{A}$ & - & 1 & 2 \\
\hline & $\mathrm{C}$ & 1 & - & - \\
\hline \multirow[t]{2}{*}{ CYP746 } & $\mathrm{A}$ & - & 1 & 2 \\
\hline & $\mathrm{C}$ & 1 & - & - \\
\hline CYP747 & A & 1 & - & 1 \\
\hline CYP772 & $\mathrm{C}$ & - & 1 & 1 \\
\hline CYP845 & $\mathrm{A}$ & 5 & - & 5 \\
\hline \multirow[t]{2}{*}{ CYP846 } & $\mathrm{A}$ & 1 & - & 2 \\
\hline & $\mathrm{B}$ & 1 & - & - \\
\hline CYP847 & $\mathrm{A}$ & 1 & - & 1 \\
\hline CYP848 & A & 1 & - & 1 \\
\hline CYP849 & A & 1 & - & 1 \\
\hline CYP850 & $\mathrm{A}$ & 1 & - & 1 \\
\hline CYP851 & A & 1 & - & 1 \\
\hline \multirow[t]{2}{*}{ CYP852 } & $\mathrm{A}$ & - & 1 & 3 \\
\hline & B & - & 2 & - \\
\hline \multirow[t]{4}{*}{ CYP853 } & $\mathrm{A}$ & - & 1 & 4 \\
\hline & B & - & 1 & - \\
\hline & $\mathrm{C}$ & - & 1 & - \\
\hline & $\mathrm{D}$ & - & 1 & - \\
\hline \multirow[t]{2}{*}{ CYP854 } & A & - & 3 & 4 \\
\hline & B & - & 1 & - \\
\hline \multirow[t]{2}{*}{ CYP855 } & $\mathrm{A}$ & - & 1 & 4 \\
\hline & $\mathrm{B}$ & - & 3 & - \\
\hline CYP856 & A & - & 2 & 2 \\
\hline \multirow[t]{3}{*}{ CYP857 } & $\mathrm{A}$ & - & 2 & 4 \\
\hline & B & - & 1 & - \\
\hline & $\mathrm{C}$ & - & 1 & - \\
\hline \multirow[t]{2}{*}{ CYP858 } & $\mathrm{A}$ & - & 1 & 2 \\
\hline & $\mathrm{B}$ & - & 1 & - \\
\hline CYP859 & A & - & 1 & 1 \\
\hline CYP860 & $\mathrm{A}$ & - & 1 & 1 \\
\hline CYP861 & A & - & 1 & 1 \\
\hline CYP862 & A & - & 1 & 1 \\
\hline CYP863 & A & - & 1 & 1 \\
\hline CYP904 & A & - & 1 & 1 \\
\hline CYP905 & A & - & 1 & 1 \\
\hline CYP906 & A & 7 & - & 7 \\
\hline CYP907 & A & 1 & - & 1 \\
\hline CYP908 & A & - & 1 & 1 \\
\hline NA & - & - & 1 & 1 \\
\hline 32 & 46 & 29 & 40 & 69 \\
\hline
\end{tabular}

The numbers in the bottom row of the table indicate the total number of P450 families (32), subfamilies (46), P450s in Chlorella sp. (29) and Coccomyxa sp. (40) and total P450 count in both species (69). Short P450 of Coccomyxa sp. is included under the "not assigned (NA)' category in the table. 


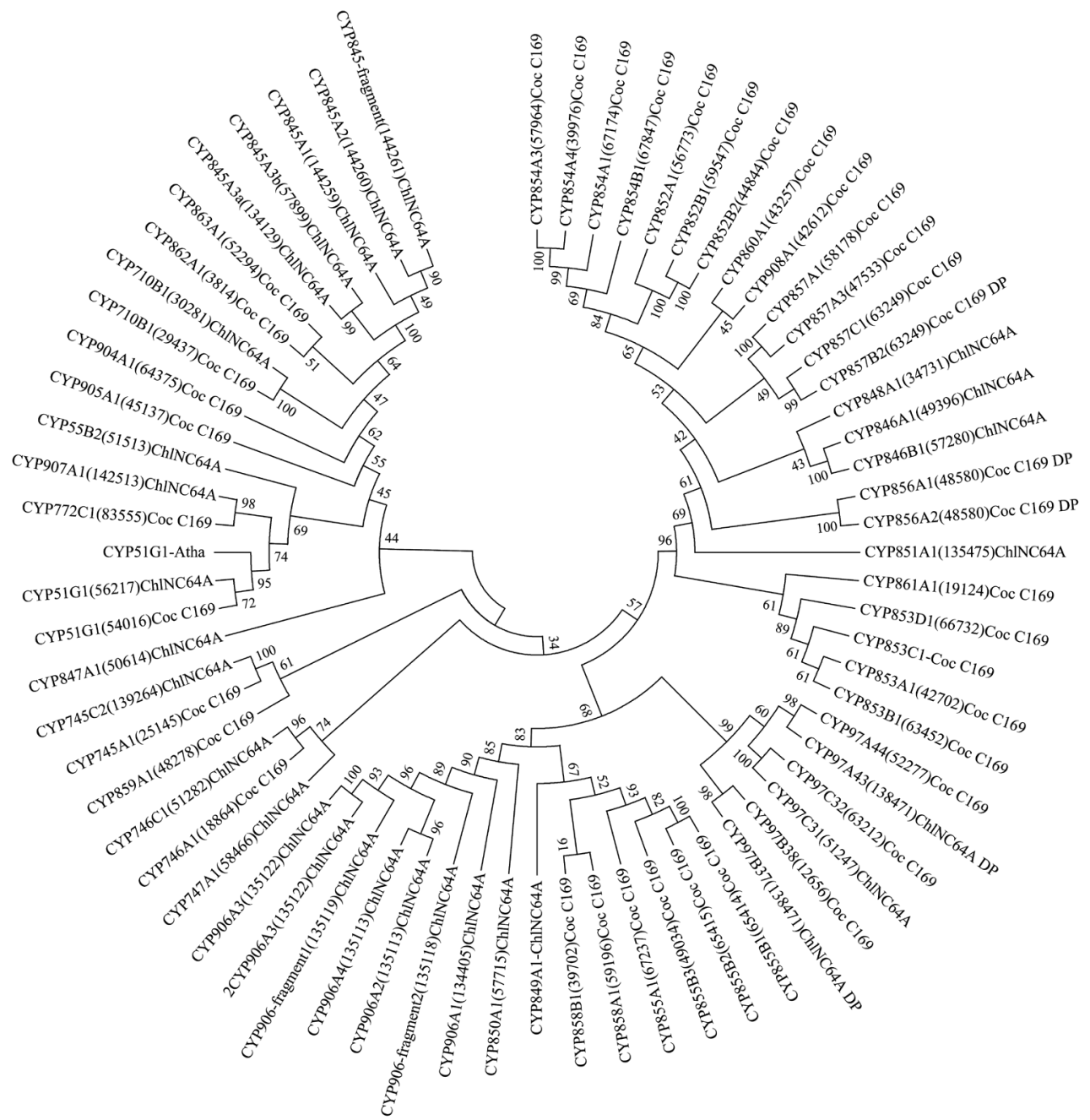

Fig. 1. Phylogenetic analysis of Coccomyxa sp. (Coc_C169) and Chlorella sp. (ChINC64A) P450s. Sixty-eight P450s were used in the analysis and CYP51 from Arabidopsis thaliana (Atha) is used as outgroup. Evolutionary history of algal P450s was performed as described in the Materials and Methods section. For each P450, family and subfamily, protein ID (parenthesis) and species information is shown. The symbol_DP in some P450s indicates two different protein predictions (genome data bases and Cytochrome P450 Homepage) for the same P450. The bootstrap values are shown next to each branch in the tree.

P450s that were $>100$ amino acids in length (protein IDs: 135119, 144261, and 135118) and one short P450 of $<100$ amino acids in length (protein ID: 65656) found in respectively Chlorella sp. and Coccomyxa sp. (Supplementary Fig. S1). The presence of short P450s in an organism is quite common and these P450s are considered short / pseudo P450s (Nelson 2009). It is not possible to assign the short / pseudo P450s with less than 100 amino acids to the correct P450 families and hence they will be kept under short / pseudo P450s. For this reason, in this study the 68 P450s that are $>100$ amino acids in length (except the one short P450 from Coccomyxa sp.) were grouped into $32 \mathrm{P} 450$ families and $46 \mathrm{P} 450$ subfamilies (Table 1).

The P450s of Coccomyxa sp. is grouped into $21 \mathrm{P} 450$ families and 32 P450 subfamilies and Chlorella sp. P450s is grouped into $16 \mathrm{P} 450$ families and $19 \mathrm{P} 450$ subfamilies. Phylogenetic analysis of P450s is critical in assigning the P450 families to the proteins around $41 \%$ identity to the named P450s. The grouping of such P450s with named $\mathrm{P} 450$ s on the phylogenetic tree plays a key role in assigning the P450 families correctly. Considering this, in this study we performed phylogenetic analysis for algae P450s (Fig. 1). Evolutionary analysis of P450s in two microalgal species revealed $\mathrm{P} 450$ s belonging to the same family and subfamilies grouped together on the tree, indicating the correct annotation of P450s (assigning the correct families and subfamilies).

Analysis of P450 families revealed the presence of twenty-seven new $\mathrm{P} 450$ families in both species. The new P450 families are CYP745-CYP747, CYP845-CYP863, 
and CYP904-CYP908. Comparative analysis of P450s between two algal species revealed the presence of five common P450 families (CYP51, CYP97, CYP710, CYP745, and CYP746). Sixteen (CYP772, CYP852-863, CYP904, CYP905, and CYP908) and 11 (CYP55, CYP747, CYP845CYP851, CYP906, and CYP907) P450 families were unique to respectively Coccomyxa sp. and Chlorella sp. Future genome sequencing of a larger number of algae species may provide insight into whether the unique $\mathrm{P} 450$ families result from the characteristic lifestyle, i.e., free-living vs symbiotic. Among 31 P450 families, CYP906 showed the highest number of P450s (7), followed by CYP97 (6 P450s) and CYP845 (5 P450s), and the CYP853-CYP855 and CYP857 P450 families showed four P450 members (Table 1).

It is well known that species enrich P450s in their genome by duplication and the P450 families that contain more member P450s are termed "P450 blooms" (Feyereisen 2011). P450 blooms were observed in animals, especially in arthropods, mainly insects (Feyereisen 2011), fungi (Syed et al. 2013, 2014), and oomycetes (Sello et al. 2015) where certain $\mathrm{P} 450$ families bloomed because of the organisms' need. Considering the lowest number of P450s and large number of $\mathrm{P} 450$ families, it is reasonable to expect no $\mathrm{P} 450$ blooming in the two model algal species. Interestingly, a few members of P450 families were found to be duplicated in both algal species (Supplementary Table S1). In Chlorella sp. P450s belonging to the CYP845 family, i.e., CYP845A1 and CYP845A2, and CYP845A3a and CYP845A3b, are located on the same scaffolds, 7 and 10 (Supplementary Table S1). In Coccomyxa sp. P450s belonging to the P450 families CYP852, CYP855, CYP857, and CYP858 are located on scaffolds 20, 5, 7 and 2 (Supplementary Table S1). Localization of member P450s of the same family / subfamily on the same scaffold in such close proximity clearly indicates the duplication process. In summary, four and eight P450 duplications were observed in Chlorella sp. and Coccomyxa sp. Intronexon analysis revealed that the intron range varied from 5-15 (Chlorella sp. P450s) and 5-30 (Coccomyxa sp. P450s) (Supplementary Table S1).

To date functional analysis of $\mathrm{P} 450 \mathrm{~s}$ from algal species has not reported. Hence, all algal P450s were considered orphans in terms of their function. However, based on homolog functions, $\mathrm{P} 450$ s' $^{\prime}$ role in algal physiology can be predicted. CYP51 P450 that is conserved across the biological kingdoms is involved in the synthesis of membrane sterols (Lepesheva and Waterman 2004). The CYP97 family known as carotenoid hydroxylase is involved in carotenoid biosynthesis (Quinlan et al. 2012, Cui et al. 2013).
CYP97A P450s are involved in hydroxylation of $\alpha$-carotene and $\beta$-carotene at $\beta$-position, whereas CYP97C P450s are involved in hydroxylation of $\alpha$-carotene at $\varepsilon$-position (Quinlan et al. 2012, Cui et al. 2013). The CYP97 family is highly conserved in plants (Werck-Reichhart et al. 2002, Hamberger and Bak 2013) and the presence of this P450 family in algal species suggests that divergence of this P450 family in autotrophs is preceded by the speciation of algae and plants. This suggests that CYP97 members play a key role in the generation of carotenoids and help algae in photosynthesis. Both algal species contain CYP710 P450s and studies have shown that CYP710A members are involved in sterol C-22 desaturation (Morikawa et al. 2006), the same function CYP61 has in fungi (Kelly et al. 1997), an important step in membrane ergosterol biosynthesis. The presence of CYP55, P450nor, in Chlorella sp. suggests that this $\mathrm{P} 450$ is possibly involved in nitric oxide reduction (Shoun et al. 2012) and plays a key role in the geochemical nitrogen cycle. Also, the CYP55 catalysed denitrification process is shown to contribute to cell growth (Tanimoto et al. 1992) by anaerobic respiration. Analysis of algal P450s at KEGG and NCBI did not yield any homologs with significant identity. Hence it is not possible to predict the remaining P450s' function in the two model algal species. The above information on algal P450s' possible role is predicted solely based on homologs and further experimentation is needed to authenticate their role in the two model algal species' physiology. The P450s function predicted in this study will at least serve as a future reference for assessing the substrate specificity of algal P450s.

\section{CONCLUSION}

Cytochrome P450 monooxygenases (P450s) play a key role in organisms' primary and secondary metabolism. Because of their stereo- and regio-specific oxidation capability, their use in various biotechnological applications has been explored. Substantial progress has been made in understanding the animal (including human), plant, fungal and bacterial P450s in terms of their distribution, phylogenetic analysis and functional analysis. However, information on microalgae P450s is limited or not reported. This study is the first report on understanding the P450s in microalgae. Here we report identification, annotation and phylogenetic analysis of $\mathrm{P} 450 \mathrm{~s}$ in two model microalgae, Coccomyxa sp. C-169 and Chlorella sp. NC64A. P450 analysis revealed the presence of 27 novel P450 families in these organisms. The polar free-living Coccomyxa sp. 
showed the highest number of P450s in its genome compared to the symbiotic Chlorella sp. Both species showed the highest P450 diversity by having 16 (Coccomyxa sp.) and 11 (Chlorella sp.) unique P450 families in their genomes. P450 duplications were also observed in these species. Based on homolog functional data, we conclude that algal P450s play a key role in their physiology, including in the synthesis of membrane ergosterols (CYP51 and CYP710), synthesis of carotenoids (CYP97) and nitric oxide reduction (CYP55). The rest of the P450s in algal species remain orphan. This study is the beginning of our understanding of microalgae $\mathrm{P} 450$ s and provides a platform for future studies, including comparative P450 analysis, functional characterization and P450s' role, if any, in freeliving and symbiotic lifestyle in microalgae.

\section{ELECTRONIC SUPPLEMENTARY MATERIAL}

Supplementary materials are available at http://e-algae.kr.

\section{ACKNOWLEDGEMENTS}

The authors are deeply grateful to Prof. David R Nelson, University of Tennessee, USA for naming the P450 families. The authors also want to thank Ms. Barbara Bradley, Pretoria, South Africa for English language editing. KS and SSM express their sincere gratitude to the Central University of Technology (CUT), Bloemfontein, Free State, South Africa for a grant from the University Research and Innovation Fund and Emerging Researcher Award (to KS). KS and SSM thank the Department of Higher Education and Training and Technology Innovation Agency, South Africa for a research grant. NTM thanks the CUT for the Vice-Chancellor's Award for Masters Studies. IKRK wants to thank the National Research Foundation-Department of Science and Technology (NRF-DST), South Africa for a Scarce Skills Development Fund masters research scholarship.

\section{REFERENCES}

Behera, S., Singh, R., Arora, R., Sharma, N. K., Shukla, M. \& Kumar, S. 2015. Scope of algae as third generation biofuels. Front. Bioeng. Biotechnol. 2:90.

Blanc, G., Agarkova, I., Grimwood, J., Kuo, A., Brueggeman, A., Dunigan, D. D., Gurnon, J., Ladunga, I., Lindquist, E., Lucas, S., Pangilinan, J., Pröschold, T., Salamov, A.,
Schmutz, J., Weeks, D., Yamada, T., Lomsadze, A., Borodovsky, M., Claverie, J. -M., Grigoriev, I. V. \& Van Etten, J. L. 2012. The genome of the polar eukaryotic microalga Coccomyxa subellipsoidea reveals traits of cold adaptation. Genome Biol. 13:R39.

Blanc, G., Duncan, G., Agarkova, I., Borodovsky, M., Gurnon, J., Kuo, A., Lindquist, E., Lucas, S., Pangilinan, J., Polle, J., Salamov, A., Terry, A., Yamada, T., Dunigan, D. D., Grigoriev, I. V., Claverie, J. -M. \& Van Etten, J. L. 2010. The Chlorella variabilis NC64A genome reveals adaptation to photosymbiosis, coevolution with viruses, and cryptic sex. Plant Cell 22:2943-2955.

Cui, H., Yu, X., Wang, Y., Cui, Y., Li, X., Liu, Z. \& Qin, S. 2013. Evolutionary origins, molecular cloning and expression of carotenoid hydroxylases in eukaryotic photosynthetic algae. BMC Genomics 14:457.

De Jesus Raposo, M. F. \& De Morais, A. M. M. B. 2015. Microalgae for the prevention of cardiovascular disease and stroke. Life Sci. 125:32-41.

Feyereisen, R. 2011. Arthropod CYPomes illustrate the tempo and mode in P450 evolution. Biochim. Biophys. Acta. 1814:19-28.

Grossman, A. R. 2005. Paths toward algal genomics. Plant Physiol. 137:410-427.

Guengerich, F. P. 1995. Cytochrome P450 proteins and potential utilization in biodegradation. Environ. Health Perspect. 103(Suppl 5):25-28.

Guengerich, F. P. 2002. Cytochrome P450 enzymes in the generation of commercial products. Nat. Rev. Drug Discov. 1:359-366.

Guengerich, F. P. 2006. Cytochrome P450s and other enzymes in drug metabolism and toxicity. AAPS J. 8:E101-E111.

Hamberger, B. \& Bak, S. 2013. Plant P450s as versatile drivers for evolution of species-specific chemical diversity. Philos. Trans. R. Soc. Lond. B Biol. Sci. 368:20120426.

Heckman, D. S., Geiser, D. M., Eidell, B. R., Stauffer, R. L., Kardos, N. L. \& Hedges, S. B. 2001. Molecular evidence for the early colonization of land by fungi and plants. Science 293:1129-1133.

Ingelman-Sundberg, M. 2004. Pharmacogenetics of cytochrome P450 and its applications in drug therapy: the past, present and future. Trends Pharmacol. Sci. 25:193200.

Karakashian, S. J. \& Karakashian, M. W. 1965. Evolution and symbiosis in the genus Chlorella and related algae. Evolution 19:368-377.

Kelly, S. L., Lamb, D. C., Baldwin, B. C., Corran, A. J. \& Kelly, D. E. 1997. Characterization of Saccharomyces cerevisiae CYP61, sterol delta22-desaturase, and inhibition by azole antifungal agents. J. Biol. Chem. 272:9986-9988. 
Kgosiemang, I. K. R., Mashele, S. S. \& Syed, K. 2014. Comparative genomics and evolutionary analysis of cytochrome P450 monooxygenases in fungal subphylum Saccharomycotina. J. Pure Appl. Microbiol. 8:291-302.

Larkin, M. A., Blackshields, G., Brown, N. P., Chenna, R., McGettigan, P. A., McWilliam, H., Valentin, F., Wallace, I. M., Wilm, A., Lopez, R., Thompson, J. D., Gibson, T. J. \& Higgins, D. G. 2007. Clustal W and Clustal X version 2.0. Bioinformatics 23:2947-2948.

Lepesheva, G. I. \& Waterman, M. R. 2004. CYP51: the omnipotent P450. Mol. Cell. Endocrinol. 215:165-170.

Letunic, I. \& Bork, P. 2011. Interactive Tree of Life v2: online annotation and display of phylogenetic trees made easy. Nucleic Acids Res. 39(Suppl 2):W475-W478.

Marchler-Bauer, A., Lu, S., Anderson, J. B., Chitsaz, F., Derbyshire, M. K., DeWeese-Scott, C., Fong, J. H., Geer, L. Y., Geer, R. C., Gonzales, N. R., Gwadz, M., Hurwitz, D. I., Jackson, J. D., Ke, Z., Lanczycki, C. J., Lu, F., Marchler, G. H., Mullokandov, M., Omelchenko, M. V., Robertson, C. L., Song, J. S., Thanki, N., Yamashita, R. A., Zhang, D., Zhang, N., Zheng, C. \& Bryant, S. H. 2011. CDD: a conserved domain database for the functional annotation of proteins. Nucleic Acids Res. 39:D225-D229.

Morikawa, T., Mizutani, M., Aoki, N., Watanabe, B., Saga, H., Saito, S., Oikawa, A., Suzuki, H., Sakurai, N., Shibata, D., Wadano, A., Sakata, K. \& Ohta, D. 2006. Cytochrome P450 CYP710A encodes the sterol C-22 desaturase in Arabidopsis and tomato. Plant Cell 18:1008-1022.

Nelson, D. R. 1998. Cytochrome P450 nomenclature. Methods Mol. Biol. 107:15-24.

Nelson, D. R. 2006. Cytochrome P450 nomenclature, 2004. Methods Mol. Biol. 320:1-10.

Nelson, D. R. 2009. The cytochrome p450 homepage. Hum. Genomics 4:59-65.

Nelson, D. R. 2013. A world of cytochrome P450s. Philos. Trans. R Soc. Lond. B Biol. Sci. 368:20120430.

Nelson, D. R., Kamataki, T., Waxman, D. J., Guengerich, F. P., Estabrook, R. W., Feyereisen, R., Gonzalez, F. J., Coon, M. J., Gunsalus, I. C., Gotoh, O., Okuda, K. \& Nebert, D. W. 1993. The P450 superfamily: update on new sequences, gene mapping, accession numbers, early trivial names of enzymes, and nomenclature. DNA Cell Biol. 12:1-51.

Paternolli, C., Antonini, M., Ghisellini, P. \& Nicolini, C. 2004. Recombinant cytochrome P450 immobilization for biosensor applications. Langmuir 20:11706-11712.

Quinlan, R. F., Shumskaya, M., Bradbury, L. M. T., Beltrán, J., Ma, C., Kennelly, E. J. \& Wurtzel, E. T. 2012. Synergistic interactions between carotene ring hydroxylases drive lutein formation in plant carotenoid biosynthesis. Plant Physiol. 160:204-214.
Sello, M. M., Jafta, N., Nelson, D. R., Chen, W., Yu, J. -H., Parvez, M., Kgosiemang, I. K. R., Monyaki, R., Raselemane, S. C., Qhanya, L. B., Mthakathi, N. T., Mashele, S. S. \& Syed, K. 2015. Diversity and evolution of cytochrome P450 monooxygenases in Oomycetes. Sci. Rep. 5:11572.

Shoun, H., Fushinobu, S., Jiang, L., Kim, S. -W. \& Wakagi, T. 2012. Fungal denitrification and nitric oxide reductase cytochrome P450nor. Philos. Trans. R. Soc. Lond. B Biol. Sci. 367:1186-1194.

Specht, E. A. \& Mayfield, S. P. 2014. Algae-based oral recombinant vaccines. Front. Microbiol. 5:60.

Stamatakis, A. 2006. RAxML-VI-HPC: maximum likelihoodbased phylogenetic analyses with thousands of taxa and mixed models. Bioinformatics 22:2688-2690.

Syed, K., Nelson, D. R., Riley, R. \& Yadav, J. S. 2013. Genomewide annotation and comparative genomics of cytochrome P450 monooxygenases (P450s) in the polypore species Bjerkandera adusta, Ganoderma sp. and Phlebia brevispora. Mycologia 105:1445-1455.

Syed, K., Shale, K., Pagadala, N. S. \& Tuszynski, J. 2014. Systematic identification and evolutionary analysis of catalytically versatile cytochrome P450 monooxygenase families enriched in model basidiomycete fungi. PLoS ONE 9:e86683.

Syed, K. \&Yadav, J. S. 2012. P450 monooxygenases (P450ome) of the model white rot fungus Phanerochaete chrysosporium. Crit. Rev. Microbiol. 38:339-363.

Tanimoto, T., Nakahara, K. \& Shoun, H. 1992. Diauxic growth of Fusarium oxysporum during aerobic culture in the presence of nitrate/nitrite. Biosci. Biotechnol. Biochem. 56:2058-2059.

Tiron, O., Bumbac, C., Patroescu, I. V., Badescu, V. R. \& Postolache, C. 2015. Granular activated algae for wastewater treatment. Water Sci. Technol. 71:832-839.

Torres, M. A., Barros, M. P., Campos, S. C. G., Pinto, E., Rajamani, S., Sayre, R. T. \& Colepicolo, P. 2008. Biochemical biomarkers in algae and marine pollution: a review. Ecotoxicol. Environ. Saf. 71:1-15.

Urlacher, V. B. \& Eiben, S. 2006. Cytochrome P450 monooxygenases: perspectives for synthetic application. Trends Biotechnol. 24:324-330.

Wang, H. -M. D., Chen, C. -C., Huynh, P. \& Chang, J. -S. 2015. Exploring the potential of using algae in cosmetics. Bioresour. Technol. 184:355-362.

Werck-Reichhart, D., Bak, S. \& Paquette, S. 2002. Cytochrome P450. Arabidopsis Book 1:e0028.

Zhang, F., Rodriguez, S. \& Keasling, J. D. 2011. Metabolic engineering of microbial pathways for advanced biofuels production. Curr. Opin. Biotechnol. 22:775-783. 